\title{
Sequencing Analysis of Local Avian Coronavirus Isolated from Infected Broiler Chickens in Babylon Province, Iraq
}

\author{
Haider Abass Al-Saegh ${ }^{1}$, Haider Tuma Kaab ${ }^{1}$, Samer Sadeq Hameed ${ }^{2}$, and Husam Muhsen Abdulwahab ${ }^{1}$ \\ ${ }^{1}$ Department of Pathology and Poultry Diseases, Faculty of Veterinary Medicine, University of Kufa, Iraq \\ ${ }^{2}$ Department of Pathology and Poultry Diseases, College of Veterinary Medicine, University of Baghdad, Iraq \\ *Corresponding author's email: haidert.mehde@uokufa.edu.iq; ORCD: 0000-0002-8016-4595
}

Received: 28 September 2021

Accepted: 17 November 2021

\begin{abstract}
Infectious bronchitis (IB) is one of the important contagious diseases in the poultry industry, through which genome alternation can lead to a newly modified IB strain. Many IB outbreaks in recent years have occurred in Babylon, Iraq, even with the implementation of a vaccination program. Therefore, the current study aimed to investigate the IB virus genome to identify the circulating strain. In this regard, any respiratory signs in broiler chickens were initially diagnosed as IB in seven farms of Babylon province, Iraq, from January to March 2021 leading to high economic loss. A total of 25 serological tests indicated infection with IB disease. Then, Flinders Technology Associates cards loaded with samples were sent to AniCon Labor $\mathrm{GmbH}$ Laboratory diagnostic in Germany for identification by extraction and sequencing the fragment of the S1 spike protein-coding gene. In the next step, the viral sequences were compared with the globally known strains of vaccines and field strains in the GenBank database using the NCBI. The results indicated a high similarity of the strain MZ520128 in the current investigation with IQ1 (MH747093.1) and Israeli (IS/1494/06) strains by $98.3 \%$ and $81.8 \%$, respectively. Furthermore, the similarity of the current isolate with vaccine strains was reported as $24-43 \%$. This variance among the current isolates with other strains could explain the reasons the vaccination strains and programs provide poor protection against the field infected by IBV. The current isolate of MZ520128 was a circulating pathogen with economic losses and the commercially available vaccine did not provide enough level to stand against the incidence of the disease.
\end{abstract}

Keywords: Avian coronavirus, Broiler chicken infectious bronchitis, SI protein sequence

\section{INTRODUCTION}

Infectious bronchitis disease is one of the important viral diseases in the poultry industry with a global effect on the industry. The infectious bronchitis virus (IBV) induces severe respiratory and acute diseases in chickens and is considered contagious in the poultry industry (Cavanagh, 2007). Recognition of IBV strain helps to control the disease incidence (Bande et al., 2016). Infectious bronchitis virus is one member of the Coronaviridae and the genus is Gamma coronavirus. The virus is RNA genome as a single-stranded genome $(\sim 30 \mathrm{~kb})$ with several open reading frames (King et al., 2018). The $\mathrm{N}$ gene of the IBV is a nucleocapsid gene that remains unchanged within the virus in contrast to the spike (particularly s1) genes which appear in multiple forms in IB viruses (Valastro et al., 2016).

Both genetic recombination and mutation are more likely to consequence IBV genome alteration (Haroldo et al., 2012). Therefore, it could lead to a change in virulence and virus tissue tropism when the mutation occurred in the S1 gene (Hassan et al., 2019). Consequently, IBV genome alteration could encourage the spread of the virus widely, creating huge economic losses as a result of the newly modified strains (Valastro et al., 2016; Hassan et al., 2019). Unfortunately, the cross-reaction among a variety of the worldwide identified genotypes or serotypes of the IBV is barely present (Martin et al., 2017). Recombination of the genetic material of the IBV among heterologous strains of different genotypes has been recorded in South Korea after the development of new recombinant IBVs (Youn et al., 2021). One of the reliable genomic identification of different strains of the IBV is the SI gene (Moreno et al., 2017; Abozeid and Naguib, 2020). Thus, the detection of the SI gene is crucially important to implement a control program and build up the epidemiological map of the disease. The real-time polymerase chain reaction (RT-PCR) technique with the nucleotide sequence of the SI gene is the routine mechanism employed for genomic identification of the 
IBV strains using a GenBank database from the NCBIbased BLAST website.

Regarding the conducted research in the field, one study in Iraq has reported the molecular features of IBV (Sul/01/09) in broiler chickens found in the North of Iraq (Zana et al., 2011). The S1 indicated the most genetic and phenotypic changeability of many IBV strains (Cavanagh, 1983; Cavanagh and Davis, 1986; Kusters et al., 1987). Therefore, IBV strains can be considered the best target to investigate variability. In this regard, the current study aimed to examine the genetic characteristics of this field strain by investigating the $\mathrm{S} 1$ gene and comparing it with other previously reported isolates to enhance vaccine protection and control the incidence of IBV disease.

\section{MATERIALS AND METHODS}

\section{Ethical approval}

All the procedures involved in the current study were permitted by the scientific and animal care committee in the department of the pathology and poultry disease in the College of Veterinary Medicine University of Kufa and Baghdad, Iraq.

\section{Sample collection}

All specimens tracheal swapes and tissue samples (liver, trachea, and lung) were collected from different Ross 308 broiler chicken farms located in Babylon province, Iraq. A total of 70 samples were used for the initial diagnosis by a rapid serological test. Specimens were collected during the outbreak of the IBD from January to March 2021. All broiler chickens' farms suffering from respiratory signs were vaccinated with attenuated IB vaccine available commercially (NOBILIS ${ }^{\circledR}$ IB Primo QX (QI01AD07, EMEA/V/C/002802, The Netherlands). Generally, respiratory symptoms began on Ross 308 flocks aged 12- 24 days with a total number of 120000 birds in 7 different farms in Babylon province. Clinically, respiratory signs were the most dominant signs, and the clinical symptoms were referred to as suspected infection with IBV. Post mortem findings were carried out, and gross pathological lesions were reported.

\section{Rapid detection of infectious bronchitis virus antigen}

The rapid test of IBV antigen detection was carried out in 30 tracheal swabs by Test Kit (RG1513DD, Bionote, Korea) which were used for serological diagnosis. The test was based on chromatographic immunoassay for detection of the virus in avian swab samples. The test procedure was conducted according to the manufacturer's instructions (Hewson et al., 2009).

\section{Extraction of RNA}

Cards of the Flinders technology associates (FTA, Whatman ${ }^{\circledR}$ FTA $^{\circledR}$ card technology WHAWB120205) were used for genomic extraction from the pooled samples (liver, trachea, and lung) with four designated areas per card. A $100 \mu \mathrm{L}$ was ready for lysing cells, denaturing the IBV proteins, and protecting nucleic acids against the damage from nucleases enzymes, ultraviolet radiation, and oxidation. In the next step, the card was stored in a plastic bag at room temperature $21^{\circ} \mathrm{C} \pm 3$ (Ganapathy et al., 2015; Manswr et al., 2018). The FTA cards with loaded RNA of the IBV materials were shipped to Germany. The PCR product clean-up and sequencing were carried out by the sequencing facility of AniCon Labor $\mathrm{GmbH}$ (Muehlenstraße 13a 49685 Hoeltinghausen Germany). These FTA cards were processed for the extraction of the IBV RNA by $\mathrm{Kylt}^{\circledR}$ RNA/DNA Purification Kit (No 31314 / 31315). The procedure was performed according to the manufacturer's protocol (Kylt_RNA-DNAPurification_Rev006_2, Ganapathy et al., 2015; Manswr et al., 2018).

\section{qPCR}

The quantitative PCR (qPCR) technique was run by AniCon Labor $\mathrm{GmbH}$ in Germany. In brief, the qPCR methods were used to detect IBV and verify the obtained strains. Hybridization of the qPCR probe-based chemistry was used with the primers of forward, 5'-CGG AAC AAA AGA CMG ACT TAG T-3'; and reverse, 5'-CCA TTA AAC AGA CTT TTT AGG TCT G-3' (Le et al., 2019). The RT- PCR technique was run according to the cycle conditions of $50^{\circ} \mathrm{C}$ for 10 minutes and $95^{\circ} \mathrm{C}$ for 1 minute (denaturation), then 42 cycles of $95^{\circ} \mathrm{C}$ for 10 seconds, $60^{\circ} \mathrm{C}$ for 1 minute (Alhatami et al., 2020).

\section{Sequencing of S1 gene products and GenBank accession number}

The RT-PCR product clean-up and sequencing were carried out by the sequencing facility of AniCon Labor GmbH Germany. Sequences of the Iraqi-strain S1 gene were available in the GenBank database to be compared with other isolates of the IBV.

\section{Location and phylogenetic analysis of the sequence}

Sequencing and phylogenetic analyses of the current IBV were achieved by AniCon Laboratory diagnostic 
results in comparison with other IBV strains, which have previously been reported to the NCBI database and vaccine database. A $500 \mathrm{bp}$ fragment of the S1 spike protein-coding gene was sequenced and phylogenetically analyzed. S1 gene sequence was compared with commercial vaccine strains and sequences of IBV previously reported in the GenBank database using the NCBI website search. The submission ID was MZ520128 to the GenBank to get the accession number of the nucleotide and amino acid sequence of the current study to isolate the $\mathrm{S} 1$ gene. The sequences were investigated by DNAstar software (DNASTAR, Madison, WI, USA) and Molecular Evolutionary Genetics Analysis (MEGA version 6) $X$ software was used to construct the phylogenetic tree (Tamura et al., 2013).

\section{RESULTS}

\section{Clinical signs and postmortem examinations}

The respiratory clinical symptoms were the most common signs in Ross 308 broiler chickens (more than $60 \%$ of the flocks in the current study) referring to the initial diagnosis of infection with IB disease. The death rate of the birds reached $20-25 \%$ for about 10 days. The respiratory signs were noticed in about 100 birds per farm. These signs included difficulty in breathing with noisy sounds, dullness, coughing, and sneezing. Pathological changes investigated by carrying out postmortem dissection in about 100 birds per farm included congestion and inflammatory exudate in the tracheal, and cheesy materials that partially closed the trachea as well as fibrinous airsacculitis. Moreover, there were instances of enlargement and congestion of kidneys and marbled with urate in the nephrons and ureters.

\section{Serological rapid infectious bronchitis virus antigen detection \\ Out of 30 from Ross 308 broiler chickens, 20} tracheal swaps were $100 \%$ positive for the IBV antigen detection.

\section{Real-time PCR}

The genomic RNA of the virus loaded on the FTA cards with the sample number (MZ520128) revealed positive results with species-specific and IBV variant-specific RT-
PCR (Table 1) besides other detected viral antigens Influenza type A, paramyxovirus pathogen, and nonpathogenic types).

Table 1. Infectious bronchitis virus or Avian corona virus, recognition by species-specific and variant-specific sample number MZ520128 Flinders technology associates card (4 spots pooled of liver, trachea, and lung tissues)

\begin{tabular}{lll}
\hline Pathogen & Cycle threshold & Result \\
\hline Influenza virus type A & 22.7 & Positive \\
\hline Influenza type A H5N1 & Both H5 nor N1 detectable & Negative \\
\hline $\begin{array}{l}\text { Avian Paramyxovirus } \\
\text { serotype 1(ND) }\end{array}$ & 19.9 & Positive \\
\hline $\begin{array}{l}\text { Avian Paramyxovirus } \\
\text { serotype 1(ND) Pathotype }\end{array}$ & CT PMV-1 $(19,1)$ & Velo/meso \\
\hline CT lentogenic Negative & Positive \\
\hline
\end{tabular}

\section{Sequence of the $S 1$ gene products}

A $500 \mathrm{bp}$ fragment of the S1 spike coding gene was sequenced and phylogenetically tested as compared to the previously known vaccine and reference strains (Table 2). The high values indicate high similarity between deduced amino acid sequences of selected strains. However, the divergence of the MZ520128 isolate indicates huge differences between strains in relation to the phylogenetic analysis. A 500-bp and 730-bp fragments of the S1 protein-coding gene were sequenced by AniCon Labor $\mathrm{GmbH}$. The sequences were deposited in the NCBI GenBank under accession number MZ520128 with the name of aCoV strain IQ1 and spike glycoprotein (S1) gene.

\section{Alignment and phylogenetic tree of sequence}

The genetic similarity among the $\mathrm{S} 1$ gene sequence of the MZ520128 strain, sequences of vaccine, and other virulent strains are presented in Figure 1 and Table 2. Based on the amplified nucleotide sequence coding for the S1-spike protein of the RNA extracted from samples of the current isolate, MZ520128 is the most related strain to strain IQ1 (MH747093.1) by $98.3 \%$, followed by $81.8 \%$ of similarity to Israeli isolate (EU780077.2_IBV_isolate_IS/1494/06). However, less similarity (77\%) was observed when compared with North of Iraq, Sulaimania isolate (Sul_01_09 Irk). The isolate has a variation of $24-43.2 \%$ from the vaccine strains. 
Table 2. Similarity among infectious bronchitis virus strains, percent Identity (horizontal axis), and the variance (vertical axis) of the IBV MZ520128 to other strains

\begin{tabular}{|c|c|c|c|c|c|c|c|c|c|c|c|c|c|c|c|c|c|}
\hline \\
\hline & 1 & 2 & 3 & 4 & 5 & 6 & 7 & 8 & 9 & 10 & 11 & 12 & 13 & 14 & 15 & 16 & \\
\hline 1 & & 98.1 & 77.6 & 69.4 & 68.2 & 67.5 & 65.8 & 65.8 & 65.8 & 67.1 & 80.8 & 78.8 & 65.0 & 65.6 & 42.8 & 45.6 & 1 \\
\hline 2 & 1.9 & & 79.5 & \begin{tabular}{|l|}
69.4 \\
\end{tabular} & 68.8 & 68.2 & 67.1 & 67.1 & 67.1 & 68.4 & 80.8 & 80.1 & 66.2 & 66.9 & 42.8 & 45.6 & 2 \\
\hline 3 & 26.7 & 24.0 & & 70.5 & 72.4 & 71.8 & 66.2 & 66.2 & 66.9 & 67.5 & 84.0 & 84.6 & 67.9 & 68.6 & 41.4 & 41.9 & 3 \\
\hline 4 & 39.2 & 39.2 & 37.4 & & 86.6 & 85.4 & 65.8 & 65.8 & 65.2 & 67.1 & 70.5 & 70.5 & 69.4 & 70.1 & 40.8 & 41.6 & 4 \\
\hline 5 & 41.4 & 40.3 & 34.4 & \begin{tabular}{|l|}
14.8 \\
\end{tabular} & & 87.3 & 66.4 & 66.5 & 65.8 & 67.7 & 71.2 & 70.5 & 68.2 & 68.8 & 38.8 & 40.3 & 5 \\
\hline 6 & 42.5 & 41.4 & 35.4 & \begin{tabular}{|l|}
16.3 \\
\end{tabular} & 14.0 & & 63.8 & 63.9 & 63.2 & 65.8 & 70.5 & 69.9 & 67.5 & 68.2 & 37.5 & 40.3 & 6 \\
\hline 7 & 45.5 & 43.2 & 44.7 & 45.5 & 44.3 & 49.1 & & 100.0 & 98.7 & 96.1 & 65.6 & 68.9 & 71.7 & 72.4 & 46.3 & 42.4 & 7 \\
\hline 8 & 45.5 & 43.2 & 44.7 & 45.5 & 44.3 & 49.0 & 0.0 & & 98.7 & 95.5 & 65.6 & 69.5 & 71.6 & 72.3 & 46.7 & 42.9 & 8 \\
\hline 9 & 45.5 & 43.2 & 43.6 & 46.6 & 45.5 & 50.2 & 1.3 & 1.3 & & 95.5 & 65.6 & 68.8 & 72.3 & 72.9 & 47.3 & 42.9 & 9 \\
\hline 10 & 43.2 & 41.0 & 42.4 & 43.2 & 42.1 & 45.5 & 4.1 & 4.7 & 4.7 & & 66.2 & 68.8 & 73.5 & 74.2 & 47.3 & 43.5 & 10 \\
\hline 11 & 22.3 & 22.3 & 18.1 & 37.4 & 36.4 & 37.4 & 45.9 & 45.9 & 45.9 & 44.7 & & 85.9 & 67.9 & 68.6 & 39.5 & 44.6 & 11 \\
\hline 12 & 24.9 & 23.1 & 17.3 & 37.4 & 37.4 & 38.5 & 40.1 & 39.1 & 40.2 & 40.2 & 15.7 & & 67.9 & 68.6 & 39.5 & 42.6 & 12 \\
\hline 13 & 47.0 & 44.7 & 41.7 & 39.2 & 41.4 & 42.5 & 35.5 & 35.7 & 34.6 & 32.6 & 41.7 & 41.7 & & 98.7 & 44.1 & 44.3 & 13 \\
\hline 14 & 45.8 & 43.6 & 40.6 & 38.2 & 40.3 & 41.4 & 34.5 & 34.6 & 33.6 & 31.7 & 40.6 & 40.6 & 1.3 & & 43.4 & 43.6 & 14 \\
\hline 15 & 101.6 & 101.6 & 106.2 & 108.5 & 116.1 & 121.4 & 90.4 & 89.2 & 87.3 & 87.3 & 113.5 & 113.5 & 97.2 & 99.4 & & 37.4 & 15 \\
\hline \multirow[t]{2}{*}{16} & 92.3 & 92.3 & 104.6 & 105.6 & 110.5 & 110.5 & 103.0 & 101.3 & 101.3 & 99.0 & 95.6 & 102.2 & 96.5 & 98.7 & 121.8 & & 16 \\
\hline & 1 & 2 & 3 & 4 & 5 & 6 & 7 & 8 & 9 & 10 & 11 & 12 & 13 & 14 & 15 & 16 & \\
\hline
\end{tabular}

\author{
MZ520128 \\ strain IQ1, Iraq \\ vaccine IB VAR2-06 \\ vaccine Nobilis IB 4-91 \\ vaccine Gallivac IB88 \\ vaccine CEVAC $\mathrm{i}$ Bird \\ vaccine Poulvac IB Primer - $\mathrm{H} 120$ \\ vaccine Bioral $\mathrm{H} 120$ \\ vaccine Nobilis IB MA5 \\ vaccine Poulvac IBMM+Ark - strain Mass \\ vaccine MEVAC IB VAR2 \\ vaccine Poulvac IB Primer - D274 clone \\ vaccine Poulvac IB QX (L-1148) \\ vaccine Nobilis IB Primo QX (D388) \\ strain D1466 \\ strain IB80
}

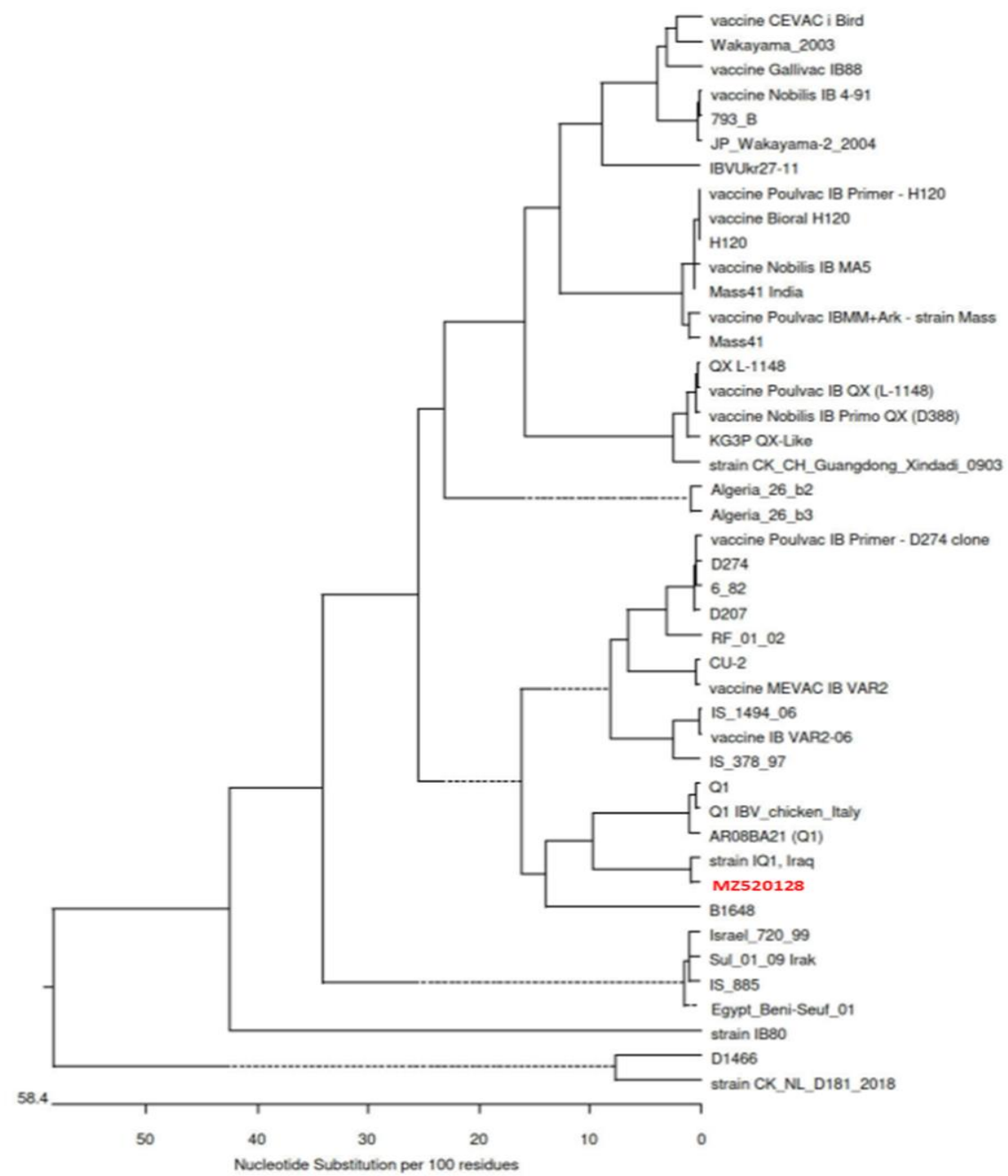

Figure 1. Phylogenic tree of infectious bronchitis virus MZ520128 according to the amplified nucleotide sequence coding for the S1-spike protein 


\section{DISCUSSION}

Generally, infectious diseases are the most important factor negatively affecting the poultry industry. One of these diseases is the IB disease, which has frequently occurred in recent years and can be classified as an endemic disease in Iraq. The IB virus was first identified in the early 1990s and has been reported in many countries in the EU and around the world (Lin and Chen, 2017). The IBV can create recombinant with the vaccine strains leading to revering virulence (Bande et al., 2015). This issue has inspired researchers to investigate the connection between the field current isolate and IB commercially vaccine (Guzmán et al., 2019). In some of the EU countries, the 793/B serotype causes the IB in poultry, even it is considered as an attenuated vaccine (Bande et al., 2015). Another example refers to the Massachusetts IB vaccine which is a widely used strain in the vaccination programs in the broiler chicken industry but it can not fully protect the broiler farms from IBV infection (Legnardi et al., 2019; Wibowo et al., 2019).

The current study can be considered the first identifying and genotyping report of IBV infected broiler chickens in Babylon, Iraq, and the Middle Euphrates Region that resembles the IQ1 (MH747093.1) and is less similar to the Israeli isolate in Iraq. The results of the sequencing and phylogenetic tree analysis indicated that the current isolate had a $98.3 \%$ and $81.8 \%$ similarity with the IQ1 (MH747093.1) and Israel 720-99, respectively. Furthermore, Alhatami et al. (2020) reported a newly isolated strain in Baghdad, Iraq, along with other regionally identified isolates from other Israel strains (Zana et al., 2011). Although Alhatami et al. (2020) isolated IBV from layer chickens, the current isolate was from broiler chickens. In the south of Iraq, Seger et al. (2016) isolated the IBV strain 793-B and Massachusetts from broiler chickens.

The Baghdad isolates of IBV from layers reported by Alhatami et al. (2020) have indicated a high similarity with Israel variant 2, IS 1494 which is another Israeli strain. This strain could be more related to the layer chickens than broilers. Therefore, the comparison of IBV isolates obtained from different regions of Iraq revealed large alterations in homology. Nevertheless, the nephron pathological lesions in broiler chickens resulted from infection with the Sulaimaniah isolate (Sul/01/09), and the virus was detected in kidney specimens but had a high similarity to the current strains isolated from the trachea .

The assumed amino acid sequence of the current isolated and amplified S1 gene of MZ520128 in the range of $24-43.2 \%$ differed from that of vaccine strains, such as Nobilis IB 4-91, CEVAC I Bird, and Bioral H120, which are commonly used in Babylon province. This variation is most likely to stand behind the reason for the poor protection of vaccines in this region, at least in these farms subjected to sample collection for the current study. The current results provide deep insight into the variance in strains of the IBV in Iraq generally and the south of Iraq particularly. More studies of IBV are required to develop a vaccine that protects against field infection.

\section{CONCLUSION}

The IBV MZ520128 isolate is the most similar strain to the Iraq strain IQ1 (MH747093.1). More likely, it is the most circulated IBV strain in broiler farms in Iraq. Despite carrying out routine vaccination programs in broiler farms, the protection against the diseases is still limited and more economic loss has been reported. Therefore, there is a need to conduct more studies addressing the most effective vaccine strain with high protection from IBV respiratory infection.

\section{DECLARATION}

\section{Authors' contribution}

All authors contributed equally to this work.

\section{Acknowledgment}

The researchers offer their gratitude to Dr Ali Hadi for his cooperation in depositing the sequence of the current isolate in the GenBank.

\section{Competing interests}

The authors declare that they have no conflicts of interest for this paper.

\section{Ethical considerations}

The results (or any part of them) used in the manuscript have not been sent for publication to any other journal nor have they already been published. The authors declare that they have checked the manuscript for plagiarism and there is no data fabrication or redundancy. The performed experiment complied with current laws and written consent of the Scientific Ethnic Committee in the department of the pathology and poultry diseases in the College of Veterinary Medicine University of Kufa and Baghdad. 


\section{REFERENCES}

Abozeid HH, and Naguib MM (2020). Infectious bronchitis virus in Egypt: Genetic diversity and vaccination strategies. Veterinary Sciences, 7: 204-213. DOI: https://www.doi.org/10.3390/vetsci7040204

Alhatami AO, Alaraji F, Abdulwahab HM, and Khudhair YI (2020). Sequencing and phylogenetic analysis of infectious bronchitis virus variant strain from an outbreak in egg-layer flocks in Baghdad, Iraq. Veterinary World, 13(7): 1358-1362. Available at: https://www.ncbi.nlm.nih.gov/pmc/articles/PMC7429401/

Bande F, Arshad SS, Omar AR, and Bejo MH, Abubakar MS, and Abba Y (2016).Pathogenesis and diagnostic approaches of avian infectious bronchitis. Advanced Virology, pp. 1-11. DOI: https://www.doi.org/10.1155/2016/4621659

Bande F, Arshad SS, Bejo MH, Moeini H, and Omar AR (2015). Progress and challenges toward the development of vaccines against avian infectious bronchitis. Journal Immunology Research, pp. 1-12. DOI: https://www.doi.org/10.1155/2016/4621659

Cavanagh D (2007). Coronavirus avian infectious bronchitis virus. Veterinary Research, 38: 281-297. DOI: https://www.doi.org/10.1051/vetres:2006055

Cavanagh D (1983). Coronavirus IBV: Structural characterization of the spike protein. Journal of General Virology, 64: 2577-2583. DOI: https://www.doi.org/10.1099/0022-1317-64-12-2577

Cavanagh D, and Davis PJ (1986). Coronavirus IBV: Removal of spike glycopolypeptide $\mathrm{S} 1$ by urea abolishes infectivity and haemagglutination but not attachment to cells. Journal of General Virology, 67: 1443. DOI: https://www.doi.org/10.1099/0022-1317$\underline{67-7-1443}$

Ganapathy K, Ball C, and Forrester A (2015). Genotypes of infectious bronchitis viruses circulating in the Middle East between 2009 and 2014. Virus Research, 2(210): 198-204. DOI: https://www.doi.org/10.1016/j.virusres.2015.07.019

Guzmán M, Sáenz L, and Hidalgo H (2019). Molecular and antigenic characterization of GI-13 and GI-16 avian infectious bronchitis virus isolated in chile from 2009 to 2017 regarding 4/91 vaccine $\begin{array}{llll}\text { introduction. } & \text { Animals, } & 9(9): & 656 .\end{array}$ https://www.doi.org/10.3390/ani9090656

Haroldo T, Vicky L, and Mark WJ (2012). Genetic diversity and selection regulates evolution of infectious bronchitis virus. Avian Disiseas, 56(3):449-455.DOI: https://www.doi.org/10.1637/10072020212-Review.1

Hassan MSH, Ojkic D, Coffin CS, Cork SC, van der Meer F, and AbdulCareem MF (2019). Delmarva (DMV/1639) infectious bronchitis virus (IBV) variants isolated in eastern Canada show evidence of recombination. Viruses, 11: 1054 DOI: https://www.doi.org/10.3390/v11111054

Hewson K, Noormohammadi AH, Devlin JM, Mardani K, and Ignjatovic J (2009). Rapid detection and non-subjective characterisation of infectious bronchitis virus isolates using high-resolution melt curve analysis and a mathematical model. Archives of Virology, 154: 649-660. DOI: https://www.doi.org/10.1007/s00705-009-0357-1

King AMQ, Lefkowitz EJ, Mushegian AR, Adams MJ, Dutilh BE, Gorbalenya AE, Harrach B, Harrison RL, Junglen S, Knowles NJ et al. (2018). Changes to taxonomy and the international code of virus classification and nomenclature ratified by the international committee on taxonomy of viruses. Archives of Virology, 163(9): 2601-2631. Available https://link.springer.com/article/10.1007\%2Fs00705-018-3847-1

Kusters JG, Niesters HGM, Bleumink-Pluym N, Davelaar FG, and
Horzinek MC (1987). Molecular epidemiology of infectious bronchitis virus in the Netherlands. Journal of General Virology, 68: 343. DOI: https://www.doi.org/10.1099/0022-1317-68-2-343

Le TB, Lee HJ, Le VP, and Choi KS (2019). Multiple genotypes of avian infectious bronchitis virus circulating in Vietnam. Korean Journal of Poultry Science, 46(2): 127-136. DOI: http://www.doi.org/10.5536/KJPS.2019.46.2.127

Legnardi M, Franzo G, Koutoulis KC, Wiśniewski M, Catelli E, Tucciarone CM, and Cecchinato M (2019). Vaccine or field strains: The jigsaw pattern of infectious bronchitis virus molecular epidemiology in Poland. Poultry Science, 98(12): 6388-6392. DOI: https://www.doi.org/10.3382/ps/pez473

Lin SY, and Chen HW (2017). Infectious bronchitis virus variants: Molecular analysis and pathogenicity investigation. International Journal of Molecular Sciences, 18(10): 2030. DOI: https://www.doi.org/10.3390/ijms18102030

Manswr B, Ball C, Forrester A, Chantrey J, and Ganapathy K (2018). Evaluation of full S1 gene sequencing of classical and variant infectious bronchitis viruses extracted from allantoic fluid and FTA cards. Avian Pathology, 47(4): 418-426. DOI: https://www.doi.org/10.1080/03079457.2018.1471196

Martin E, Brash M, Stalker M, and Ojkic D (2017). Using phylogenetic analysis to examine the changing strains of infectious bronchitis virus infections in Ontario over time. In: Proceedings of the 16th annual meeting of the Canadian animal health laboratorians Network, Guelph, On, Canada, pp. 4-7. Available at: http://cahlnrctlsa.com/wp-content/uploads/2014/11/3-CAHLN-AHL-IBVphylogenetic-analysis-2017.pdf

Moreno A, Franzo G, Massi P, Tosi G, Blanco A, Antilles N, Biarnes M, Majo N, Nofrarias M, Dolz R et al. (2017). A novel variant of the infectious bronchitis virus resulting from recombination events in Italy and Spain. Avian Pathology 46(1): 28-35. DOI: https://www.doi.org/10.1080/03079457.2016.1200011

Seger W, Langeroudi AG, Karimi V, Madadgar O, Marandi MV, and Hashemzadeh M (2016). Prevalence of avian infectious bronchitis virus in broiler chicken farms in South of Iraq, 2014-2015. Veterinary Research Forum, 7(4): 317-321. Available at: https://www.ncbi.nlm.nih.gov/pmc/articles/PMC5251354/

Tamura K, Stecher G, Peterson D, Filipski A, and Kumar S (2013). MEGA6: Molecular evolutionary genetics analysis version 6.0. Molecular Biology and Evolution, 30(2): 2725-2729. DOI: https://www.doi.org/10.1093/molbev/mst197

Valastro V, Holmes EC, Britton P, Fusaro A, Jackwood MW, Cattoli G, and Monne I (2016). S1 gene-based phylogeny of infectious bronchitis virus: An attempt to harmonize virus classification. Infection, Genetics and Evolution Journal, 39: 349-364. DOI: https://www.doi.org/10.1016/j.meegid.2016.02.015

Wibowo MH, Ginting TE, and Asmara W (2019). Molecular characterization of pathogenic 4/91-like and QX-like infectious bronchitis virus infecting commercial poultry farms in Indonesia. Veterinary World, 12(2): 277-287. Available at: http://www.veterinaryworld.org/Vol.12/February-2019/15.html

Youn SY, Lee JY, Bae YC, Kwon YK, and Kim HR (2021). Genetic and pathogenic characterization of QX(GI-19) recombinant infectious bronchitis viruses in South Korea.Viruses, 13: 1163. DOI: https://www.doi.org/10.3390/v13061163

Zana HM, Rizgar RS, and Aumaid UU (2011). Isolation and molecular characterization of Sul/01/09 avian infectious bronchitis virus, indicates the emergence of a new genotype in the Middle East. Veterinary Microbiology, 15: 21. DOI: https://www.doi.org/10.1016/j.vetmic.2010.12.015 